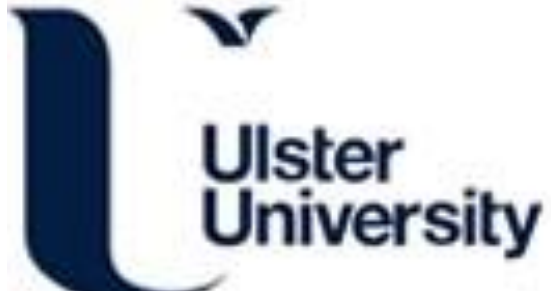

\section{Palladium Nanoneedles on Carbon Fiber: Highly Sensitive Peroxide Detection for Biomedical and Wearable Sensor Applications}

McConville, A., Mathur, A., \& Davis, J. (2019). Palladium Nanoneedles on Carbon Fiber: Highly Sensitive Peroxide Detection for Biomedical and Wearable Sensor Applications. IEEE Sensors, 19(1), 34-38. [8478226]. https://doi.org/10.1109/JSEN.2018.2872895

Link to publication record in Ulster University Research Portal

\section{Published in:}

IEEE Sensors

Publication Status:

Published (in print/issue): 01/01/2019

DOI:

10.1109/JSEN.2018.2872895

\section{Document Version}

Author Accepted version

\section{General rights}

Copyright for the publications made accessible via Ulster University's Research Portal is retained by the author(s) and / or other copyright owners and it is a condition of accessing these publications that users recognise and abide by the legal requirements associated with these rights.

\section{Take down policy}

The Research Portal is Ulster University's institutional repository that provides access to Ulster's research outputs. Every effort has been made to ensure that content in the Research Portal does not infringe any person's rights, or applicable UK laws. If you discover content in the Research Portal that you believe breaches copyright or violates any law, please contact pure-support@ulster.ac.uk. 


\title{
Palladium Nanoneedles on Carbon Fiber: Highly Sensitive Peroxide Detection for Biomedical and Wearable Sensor Applications
}

\author{
Aaron McConville, Ashish Mathur and James Davis
}

\begin{abstract}
The development of a single carbon fiber electrode has been investigated as a potential non-enzymatic sensor capable of quantifying peroxide. Electrodeposition of palladium is shown to create nanostructured deposits with a nanoneedle and nanorod like morphology. The electrode modification is shown to be facile and the resulting sensors exhibit a high sensitivity towards the oxidation $\left(388 \mu \mathrm{A} \mathrm{mM} \mathbf{m}^{-1} \mathrm{~cm}^{-2}\right)$ and the reduction of peroxide. Interference from uric acid has been investigated and the use of Nafion ${ }^{\circledR}$ shown to greatly reduce its influence without unduly compromising the sensitivity of the sensors towards peroxide.
\end{abstract}

Index Terms - Carbon fiber, electrode, nanoneedle, nano-rod, palladium, sensor, uric, urine.

\section{INTRODUCTION}

U rinary incontinence has long been recognized as one of the most emotionally fraught issues for those suffering from dementia and, with an increasing prevalence of the disease, it is liable to have a significant impact on patients and carers $[1,2]$. It has been estimated that urinary incontinence (UI) care accounts for almost $60 \%$ of residential nursing care time with overall costs resting within the £bn region in developed countries [1-4]. Over two-thirds of elderly living within residential care require assistance in using the toilet with half of those suffering from UI [1,4]. The development and introduction of new wearable sensor systems and smart textiles that can be directly integrated within existing continence products proffer opportunities to dramatically improve continence management and improve quality of life (QoL) for many patients. In most cases however, the devices are based on simple wireless systems that detect the onset of urination through changes in conductivity of the continence pad [1]. Advances in biosensor technology and their

Manuscript received XXXX; revised XXXXX; accepted XXXXXX. Date of publication XXX; date of current version XXXX.) This work was supported by the Department for the Economy (DfE) Northern Ireland and the British Council UKIERI programme under grant number DST 2016-17 - 065. The associate editor coordinating the review of this paper and approving it for publication was XXXXXXX. (Corresponding author: James Davis)

A. McConville and J. Davis are with the Nanotechnology and Integrated Bioengineering Centre, School of Engineering at Ulster University, Jordanstown, Northern Ireland, BT37 0QB. (e-mail: mcconvillea4@ulster.ac.uk; james.davis@ulster.ac.uk)

Ashish Mathur is with the Amity Institute of Nanotechnology, Amity University, Noida 201313, India (e-mail: amathur@amity.edu) adaptation within material platforms suitable for implementation within continence products could radically increase the care potential through not simply detecting the presence of stool or urine but screening for the presence of metabolic diseases, kidney function or urinary tract infection. It can be anticipated that such conditions are more likely in the elderly and hence non- invasive routine monitoring of urine could provide a simple yet effective means of detecting the early onset of complications that will impact QoL and patient care.

There are two critical challenges to be addressed: size of the sensing structure and selectivity. The production of microelectrodes for biomedical applications has long held the interest of clinicians through providing the possibility of monitoring key disease biomarkers in situ and provide a platform for the development of a miniaturized sensor. Moreover, the use of carbon fiber in wearable technologies has already been demonstrated. In most cases such systems have focused on strain measurements rather than the direct analysis of biological species. Untreated carbon fiber, while conductive, can however be a relatively poor sensor with no inherent selectivity towards analytes and, as such, will generally require modification with chemical moieties or enzymes. In the case of latter, the analytical signal is typically acquired indirectly through the detection of peroxide released as a byproduct of the enzyme reaction. Quantification of the latter can be difficult and often requires the imposition of large overpotentials which can induce the oxidation of other matrix components and thereby compromise the analytical accuracy of the system. This could be problematic in the case of wearable sensors designed to monitor urine. Uric acid is key component of the latter and, with a relatively high concentration and ease of oxidation, would be expected to be a pernicious interference.

The present investigation reports on the deposition of a highly structured palladium layer composed of a nanoneedle forest upon commercial carbon fiber and assesses its catalytic applicability for the detection of peroxide. The influence of uric acid on the fiber response is investigated and the strategies to minimise potential interference are critically evaluated. 


\section{EXPERIMENTAL DETAILS}

Materials and Instrumentation: Chemical reagents were obtained from Sigma-Aldrich (Dorset England) and were of the highest grade available and used without further purification. Nafion ${ }^{\circledR}$ perfluorinated resin solution was $5 \%$ w/w in lower aliphatic alcohols and $\mathrm{H}_{2} \mathrm{O}$, and hydrogen peroxide stock solution $\left(\mathrm{H}_{2} \mathrm{O}_{2}\right) 30 \%$ w/w in $\mathrm{H}_{2} \mathrm{O}$. Carbon fiber (tex number 420, filament diameter $0.01 \mathrm{~mm}$, number of filaments 3000 , grade f180, epoxy sized (1.0\%)) was obtained from Goodfellow Cambridge Ltd. (Huntingdon, England). Electrochemical measurements were conducted using a PG581 potentiostat using a conventional three electrode configuration. Phosphate-buffered saline (PBS) solutions ( $\mathrm{pH}$ 7.4) were used throughout unless specified otherwise.

Electrode Fabrication: Individual carbon fibers were first separated from the supplied ribbon and adhered to sections of copper tape prior to being sandwiched between two $125 \mu \mathrm{m}$ laminate sheets pre-patterned to yield a window exposing a $4 \mathrm{~mm}$ length of the single carbon fiber. These were sealed by way of thermal lamination to form a working electrode. Palladium nanocrystals were grown onto the carbon fiber surface by way of electrodeposition, based on an adaptation of a technique described by Xu et al. (2014) [8]. A potential offset of $+46 \mathrm{mV}$ was applied (relative to a $3 \mathrm{M} \mathrm{KCl} \mathrm{Ag} / \mathrm{AgCl}$ reference electrode). Surface modification took place in an aqueous solution of $0.1 \mathrm{M} \mathrm{HCl}$ containing $1.5 \mathrm{mM}$ tetrachloropalladium $\left(\mathrm{Na}_{2} \mathrm{PdCl}_{4},\right), 20 \mathrm{mM} \mathrm{NaBr}$, and $40 \mathrm{mM}$ sodium citrate. The first deposition step involved nucleation of palladium onto the carbon fiber surface by four repeated pulses at a potential of $-0.446 \mathrm{~V}$ for $50 \mathrm{~ms}$ each, followed by a growth step in which the potential was held at $0.134 \mathrm{~V}$ for 600 s. Each electrode was rinsed with deionized water and dried with nitrogen prior to further modification.

\section{RESULTS AND DISCUSSION}

Scanning electron micrographs detailing the morphological features of the carbon fiber before and after Pd deposition are detailed in Figs 1A-1D. Upon initiating the deposition cycle, the unmodified carbon fiber (1A) is quickly transformed to a forest of Pd nanostructures (1B). The Pd nucleates at the carbon surface before the coalescing to form a continuous layer whereupon the nanoneedles develop. The initial deposition results in sharp needle like structures but as the deposition time is increased (from 900s in 1B to 1800s in 1C) the structure become more rounded. The latter is supported in the fractured fiber coating shown in Fig 1D where discrete Pd rod like projections can be seen and are typically aligned perpendicular to the fiber surface.
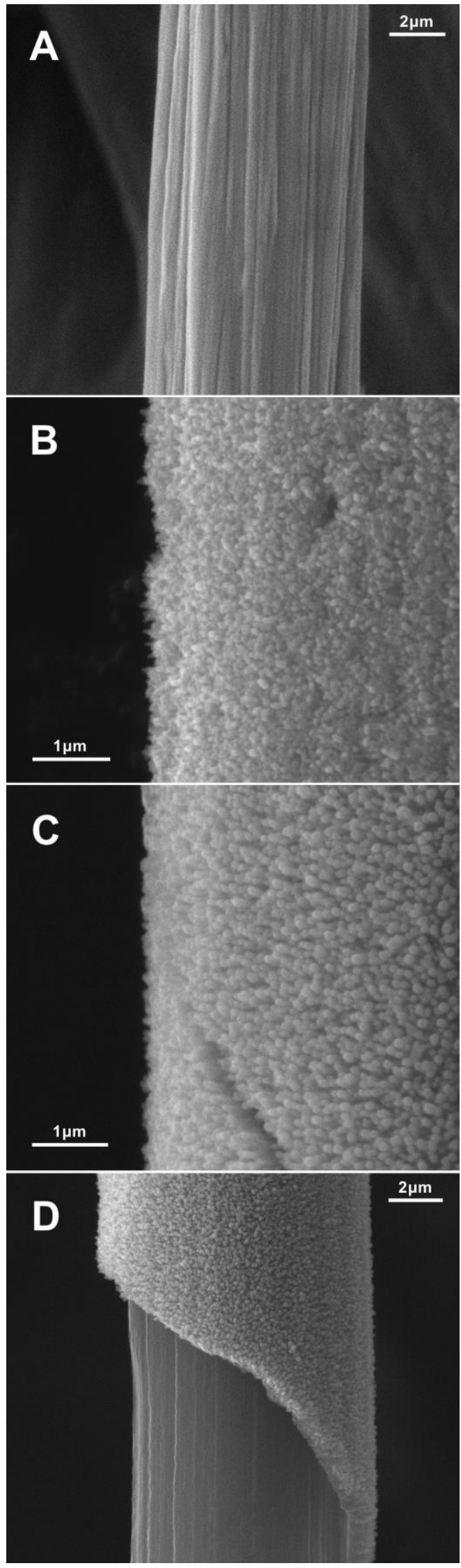

Fig. 1. Scanning electron micrographs of various morphologies of palladium deposition on single carbon fibers. 
Cyclic voltammograms highlighting the influence of the nanostructured Pd fiber towards peroxide $(0-250 \mu \mathrm{M}, \mathrm{pH} 7)$ are detailed in Fig 2. There is a dramatic increase in the oxidation (Figure 2A) and reduction (Figure 2B) processes at the Pd modified electrode compared to the unmodified carbon fiber.
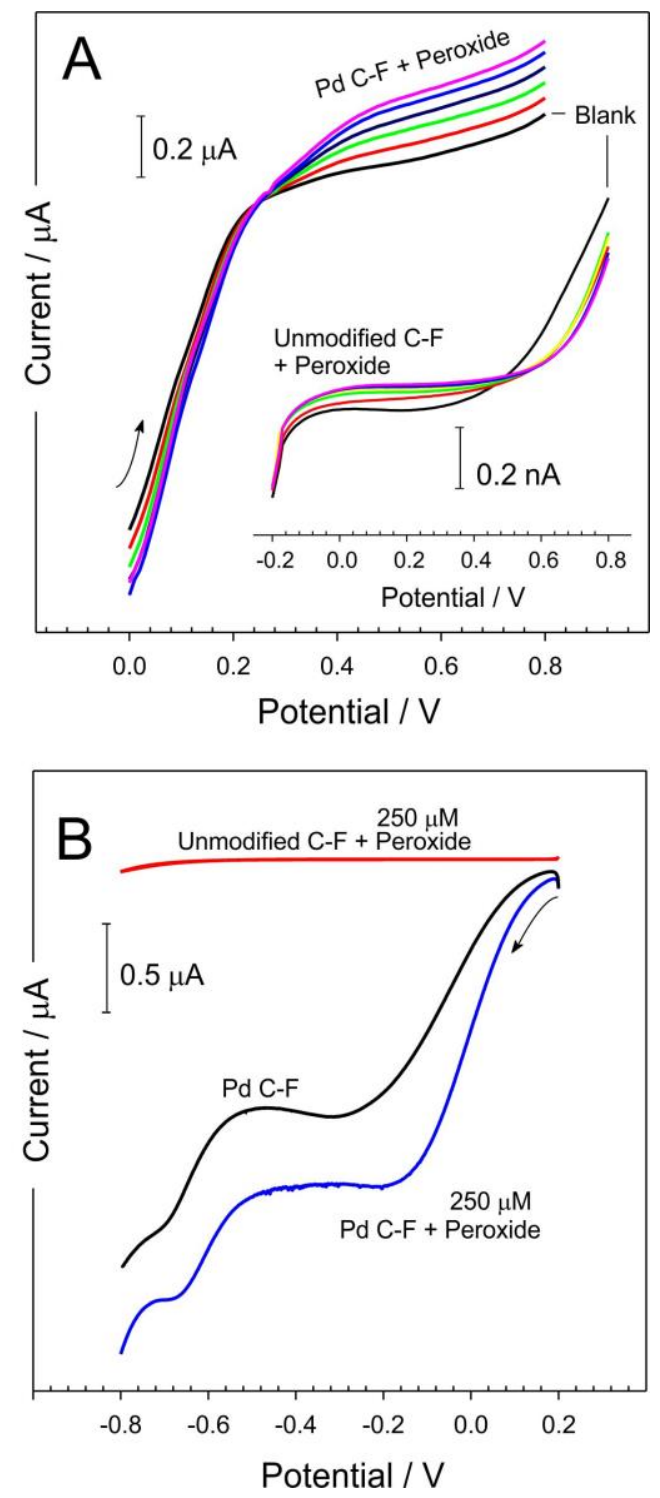

Fig. 2. A) Linear sweep voltammograms detailing the response of a $\mathrm{Pd}$ nanoneedle carbon fiber electrode towards peroxide $(0-250 \mu \mathrm{M}, \mathrm{pH} 7)$ and compared to the response obtained at an unmodified carbon fiber (Inset). B) Linear sweep voltammograms highlighting the response of the fiber electrodes to the reduction of peroxide in the presence of oxygen. Scan rate : $50 \mathrm{mV} / \mathrm{s}$

The sensitivity data corresponding to each modification are detailed in Table 1 and it can be seen that for the oxidation of peroxide at $+0.8 \mathrm{~V}$, the Pd coated C-F increases the sensitivity by 4 orders of magnitude over the unmodified carbon fiber. There is a wealth of studies on the modification of electrodes to confer selective and sensitive responses to peroxide and some of these are included in Table 1 for comparison. It is clear that the $\mathrm{Pd}$ modified system described here is competitive with many of those whilst also providing a much more facile means of modification [12-14].

Table 1. Electrode sensitivity towards Peroxide

\begin{tabular}{|c|c|c|c|}
\hline Electrode Type & $\begin{array}{l}\text { Detection } \\
\text { Potential } \\
\text { / V }\end{array}$ & $\begin{array}{r}\text { Sensitivity } \\
\mu \mathrm{AmM}^{-1} \mathrm{~cm}^{-2}\end{array}$ & Ref \\
\hline Unmodified C-F & +0.3 & 0.06 & TW \\
\hline Unmodified C-F & +0.8 & 0.08 & TW \\
\hline Pd Modified C-F & +0.3 & 67.12 & TW \\
\hline Pd Modified C-F & +0.8 & 312.90 & TW \\
\hline Nafion Pd C-F & +0.3 & 8.76 & TW \\
\hline Nafion Pd C-F & +0.8 & 27.71 & TW \\
\hline PdNPs-MWCNTs/GCE & +0.35 & 0.17 & 12 \\
\hline $\mathrm{ZnO} / \mathrm{Co} 3 \mathrm{O} 4 / \mathrm{NiCo} 2 \mathrm{O} 4 / \mathrm{Ni}$ & +0.55 & 388.00 & 13 \\
\hline Co304 NPs & +0.2 & 72.75 & 14 \\
\hline $\mathrm{Pd} C-\mathrm{F}$ & -0.2 & 148.89 & TW \\
\hline ER-GNO/IL-SPE & -0.2 & 78.13 & 15 \\
\hline $\mathrm{rGO} / \mathrm{ZnO} / \mathrm{GCE}$ & -0.38 & 0.01 & 16 \\
\hline Nafion/CAT/rGO/GCE & -0.45 & 7.76 & 17 \\
\hline $\mathrm{Au}-\mathrm{Pd} / \mathrm{MoS} 2 / \mathrm{GCE}$ & -0.1 & 184.90 & 18 \\
\hline
\end{tabular}

The application of a large anodic potential, while providing a high sensitivity, will nevertheless induce the opportunity for oxidizing other matrix components. It is common place to minimize the operating potential to avoid the interference from such compounds (typically uric acid in the case of urine samples) but this requires that the electrode surface is still responsive to peroxide. The lowest potential where linearity of response to peroxide is preserved was found to be $+0.3 \mathrm{~V}$. It can be seen from Table 1 that reducing the potential to $+0.3 \mathrm{~V}$ results in a deterioration in the sensitivity but, it must be noted, still remains consistent with advances in the recent literature. Similarly, the exploitation of the Pd coating for the reduction of peroxide (Fig 2B) provides a sensitivity that is again superior to many of the more procedurally complex, nanoparticle systems [15-18].

\section{INTERFERENCE}

While it is clear that the highly active Pd nanoneedle structures greatly enhance the response to peroxide, the 
question of interference at $+0.3 \mathrm{~V}$ is still pertinent. The imposition of a potential of $+0.3 \mathrm{~V}$ can still be problematic, especially in terms of minimizing the interference from uric acid. The latter is ubiquitous in biological fluids and can be a pernicious interferent as a consequence of its ease of oxidation [19-20]. The response of the Pd C-F modified electrode towards urate $(150 \mu \mathrm{M}, \mathrm{pH} 7)$ was initially assessed using cyclic voltammetry (Fig 3A). Uric acid was found to undergo oxidation at the electrode and it is clear from the voltammograms in Fig 3A that the onset of oxidation occurs at a potential liable to directly interfere with peroxide. One alternative is to exploit the reduction of peroxide rather than pursue the oxidation and thus the imposition of a reducing potential $(-0.2 \mathrm{~V})$ would effectively negate the influence of urate whilst preserving a sensitive response to peroxide. This is confirmed in Table 1 where the reduction sensitively remains highly competitive and similar approaches are commonplace in sensing designs [15-18].

The oxidation approach however is not totally redundant however as coating the Pd nanostructures with Nafion $®$. The latter is a sulfonated tetrafluoroethylene based polymer which is regularly used to minimize interference from anionic species (such as uric acid) and is regularly used as a secondary/top layer modification to sensor system [18]. The effect of the Nafion ${ }^{\circledR}$ coating on the response of the Pd C-F electrode towards uric acid $(150 \mu \mathrm{M}, \mathrm{pH} 7)$ is detailed in Fig $3 \mathrm{~A}$. In contrast to the uncoated fiber, the Nafion ${ }^{\circledR}$ layer effectively removed the urate response. The presence of the polymer does however reduce the sensitivity of the electrode towards the oxidation of peroxide as indicated by the summary results in Table 1 but having the permselective barrier enables the larger $+0.8 \mathrm{~V}$ (hence more sensitive configuration) to be applied.

The amperometric response of the Nafion-Pd-C-F electrode to peroxide and urate is highlighted in Fig 3B. It is inevitable that any subsequent biosensor design for use within a continence product/wearable system would employ amperometry rather than voltammetric means. It can be seen from Fig 3B that the electrode remains sensitive to peroxide (even at $+0.3 \mathrm{~V}$ ) with no interference from the urate additions.

\section{CONCLUSIONS}

There is an extensive literature base on the modification of electrode surfaces for the detection of peroxide but the translation of the systems to wearable devices/smart textiles can be problematic. Complexities in the fabrication processes can comprise device viability from both economic and practical perspectives. The ability to directly nanostructure a highly effective Pd coating onto carbon fiber provides a facile approach to sensor design. The response characteristics using either oxidative or reductive detection methodology has been shown to be highly competitive in comparison to recent nanoparticulate systems. Secondary modification through the application of permselective films such as Nafion can further enhance the response characteristics.
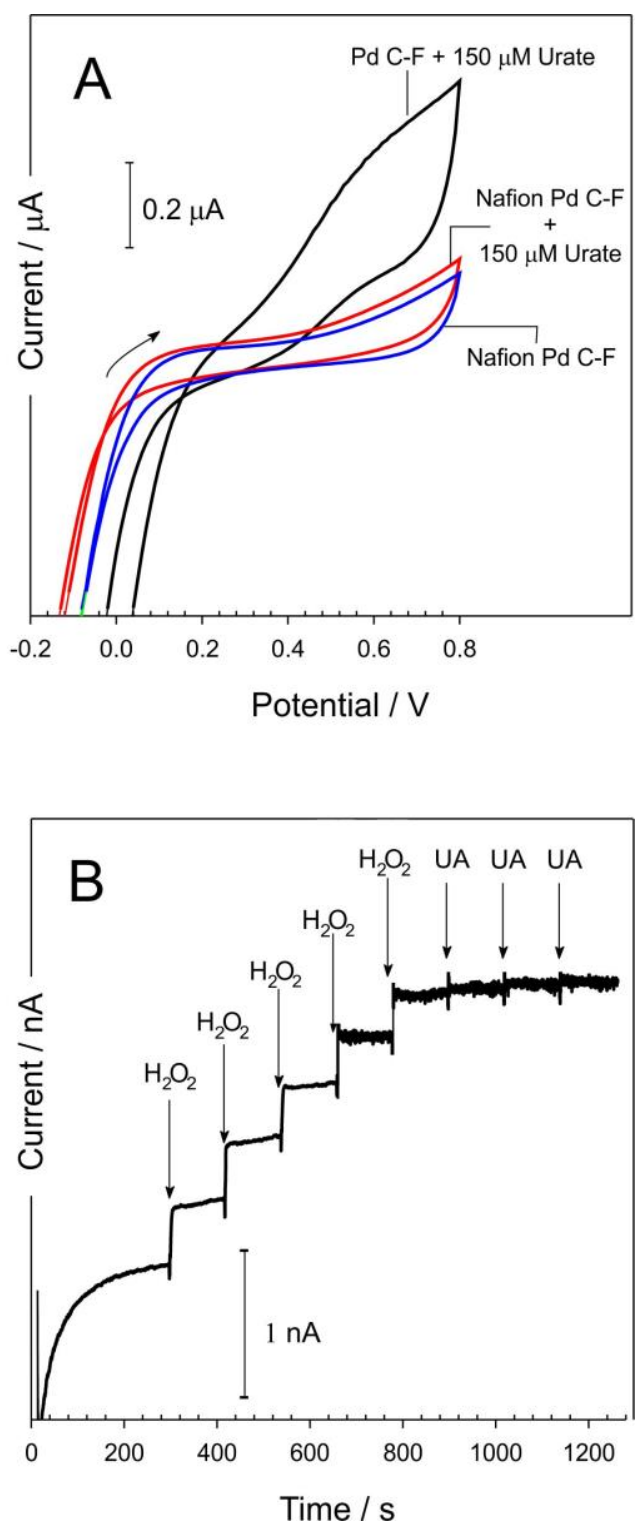

Fig. 3. A) Cyclic voltammograms detailing the response of the Pd modified carbon fiber to uric acid $(150 \mu \mathrm{M}, \mathrm{pH}$ 7) before and after coating with Nafion ${ }^{\circledR}$. B) Steady state amperometry of the Nafion ${ }^{\circledR}$ coated Pd fiber with addition of peroxide (100 $\mu \mathrm{L}$ aliquot of $0.03 \%)$ and urate $(25 \mu \mathrm{L}$ aliquots, 10 $\mathrm{mM})$ to PBS buffer solution whilst stirring, at an applied potential of $0.300 \mathrm{~V}$.

\section{REFERENCES}

1. P. Fish, V. Traynor, Sensor technology: a smart way to manage continence, Australian Journal of Dementia Care, 2, 35-37, 2013.

2. Expert Group on LUTS, Who cares? Uncovering the 
incontinence taboo in social care, 2014, Available from:

http://www.aca.uk.com/files/3414/3282/7812/Expert_G roup_Who_Cares_Uncovering_the_incontinence_tab oo_in_social_care.pdf [Last Accessed: 14/8/18]

3. L.L. Subak, J.S. Brown, S.R. Kraus, L. Brubaker, F. Lin, H.E. Richter, C.S. Bradley, D.Grady, The "Costs" of Urinary Incontinence for Women, Obstet Gynecol. 107: 908-916. 2006.

4. B. Roe, L.Flanagan, B. Jack, J. Barrett, A. Chung, C. Shaw, K.Williams, Systematic review of the management of incontinence and promotion of continence in older people in care homes: descriptive studies with urinary incontinence as primary focus, Journal of Advanced Nursing, 67, 228-250, 2011.

5. O.A. Araromi, C.J. Walsh, R.J. Wood, Hybrid carbon fiber-textile compliant force sensors for high-load sensing in soft exosuits, IEEE International Conference on Intelligent Robots and Systems Pages: 1798-1803 Published: 2017

6. W.Xu, J. Lu, W. Huo, J. Li, X. Wang, C. Zhang, X. Gu, C. $\mathrm{Hu}$, Direct growth of $\mathrm{CuCo}_{2} \mathrm{~S}_{4}$ nanosheets on carbon fiber textile with enhanced electrochemical pseudocapacitive properties and electrocatalytic properties towards glucose oxidation, Nanoscale, 10, 14304-14313, 2018.

7. C. Wang, K. Xia,M. Zhang, M. Jian, Y. Zhang, An AllSilk-Derived Dual-Mode E-skin for Simultaneous Temperature-Pressure Detection, ACS Appl. Mater. Interfaces, 9, 39484-39492, 2017.

8. Y. Li, M. Nie, Q. Wang, Facile Fabrication of Electrically Conductive Low-Density Polyethylene / Carbon Fiber Tubes for Novel Smart Materials via Multiaxial Orientation, ACS Appl. Mater. Interfaces, 10, 1005-1016, 2018.

9. S.Chen, R.Yuan, Y. Chai, F. Hu, Electrochemical sensing of hydrogen peroxide using metal nanoparticles: a review, Microchim Acta, 180, 15-32, 2013.

10. W. Chen, S.Cai, Q-Q. Ren, W. Wen, Y-D. Zhao, Recent advances in electrochemical sensing for hydrogen peroxide: a review, Analyst, 137, 49-58, 2012.

11. Xu D, Yan X, Diao P, Yin P. Electrodeposition of Vertically Aligned Palladium Nanoneedles and Their Application as Active Substrates for Surface-Enhanced Raman Scattering. J Phys Chem C, 118, 9758-68, 2014.

12. H. Hamidi, B. Haghighi, Fabrication of a sensitive amperometric sensor for $\mathrm{NADH}$ and $\mathrm{H}_{2} \mathrm{O}_{2}$ using palladium nanoparticles-multiwalled carbon nanotube nanohybrid, Materials Science and Engineering C, 62, 423-428, 2016.

13. B. Xue, K. Li, S. Gu, L. Zhang, J. Lu, Ni foamsupported $\mathrm{ZnO}$ nanowires and $\mathrm{Co}_{3} \mathrm{O}_{4} / \mathrm{NiCo}_{2} \mathrm{O}_{4}$ double-shelled nanocages for efficient hydrogen peroxide detection, Sensors and Actuators B 262, 828-
836, 2018.

14. Y. Ni, Y. Liao, M. Zheng, S. Shao, In-situ growth of $\mathrm{Co3O} 4$, nanoparticles on mesoporous carbon nanofibers: a new nanocomposite for non-enzymatic amperometric sensing of $\mathrm{H}_{2} \mathrm{O}_{2}$, Microchim. Acta, 50, 1-7, 2017.

15. J. Ping, Y. Wang, K. Fan, J. Wu, Y. Ying, Direct electrochemical reduction of graphene oxide on ionic liquid doped screen-printed electrode and its electrochemical biosensing application, Biosens. Bioelectron. 28, 204-209, 2011.

16. S. Palanisamy, S.M. Chen, R. Sarawathi, A novel nonenzymatic hydrogen peroxide sensor based on reduced graphene oxide / $\mathrm{ZnO}$ composite modified electrode, Sensors Actuators B Chem. 166, 372-377, 2012.

17. S.W. Ting, A.P. Periasamy, S.M. Chen, R. Saraswathi, Direct electrochemistry of catalase immobilized at electrochemically reduced graphene oxide modified electrode for amperometric $\mathrm{H}_{2} \mathrm{O}_{2}$ biosensor, Int. J. Electrochem. Sci. 6, 4438-4453, 2011

18. X.Li, X. Du, Molybdenum disulfide nanosheets supported Au-Pd bimetallic nanoparticles for nonenzymatic electrochemical sensing of hydrogen peroxide and glucose, Sensors and Actuators B, 239, 536-543, 2017

19. J.S.N. Dutt, M.F. Cardosi, C. Livingstone, J. Davis, Diagnostic implications of uric acid in electroanalytical measurements, Electroanalysis, 17, 1233-1243, 2005.

20. J.S.N. Dutt, C. Livingstone, M.F. Cardosi, S.J. Wilkins and J. Davis, A clinical assessment of direct electrochemical urate measurements, Talanta, $\mathbf{6 8}$, 1463-1468, 2006. 


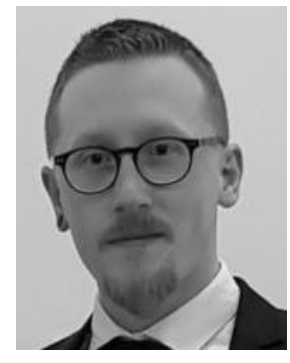

Aaron McConville received his BSc degree in Biomedical Engineering from Ulster University, Northern Ireland in 2015 after which he continued his studies within the Nanotechnology and Integrated BioEngineering Centre. He is currently pursuing a $\mathrm{PhD}$ in the same field, and has contributed to 9 publications in reputed journals. His research interests include transdermal drug delivery, associated permeation enhancement techniques and controlled release mechanisms, development and fabrication of biological sensors, medical device prototyping, and microscale additive manufacturing techniques.

During his time at Ulster University, Aaron has had significant involvement in module co-ordination, assessment, and delivery of teaching material to undergraduate students within the School of Computing and Engineering.

$\mathrm{Mr}$ McConville was the recipient of the The McColgan Innovation Award and a Diploma in Professional Practice during his undergraduate studies, and in 2018 received an award for Best Engagement on behalf of the StomaSense team for their efforts during the Lean Launchpad Programme NI.

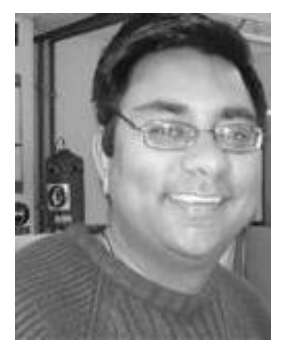

Ashish Mathur received the Ph.D. degree from the Nanotechnology and Integrated Bioengineering Centre (NIBEC), University of Ulster, Jordanstown, campus, Belfast, U.K., in 2011, the M.Tech degree in nanotechnology from the Amity Institute of Nanotechnology, Amity University, Noida, India, in 2007, and the B.Sc. and M.Sc. degrees in electronics from CSJM University, Kanpur, India, in 2003 and 2005,respectively. He has been an Assistant Professor with the Amity Institute of Nanotechnology, Amity University, Noida, India, since 2013. He was a Research Associate at NIBEC from 2010 to 2012. His research interest includes microfluid ics, sensors, carbon nanostructures, MEMS, and NEMS

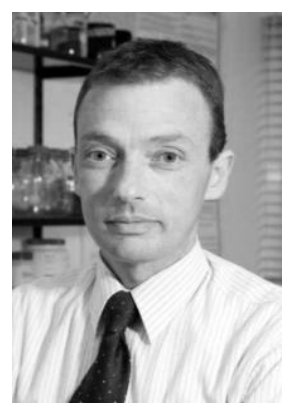

James Davis is Professor of Biomedical Sensors in the School of Engineering and is a member of the Engineering Research Institute. He received his BSc (Hons) degree in Chemistry from the University of Paisley (UK) and continued his studies there to complete a Ph.D in electron transfer mediators for biosensor applications.

His research interests are directed toward the development of new diagnostic devices for the rapid treatment of disease and injury and has published over 140 peer reviewed articles and is the author of two books. He has been the Principal Investigator/coordinator of numerous multi-centre - multi-discipline research collaborations with funding from the EPSRC, Wellcome Trust, Juvenile Diabetes Research Foundation, Heart Research UK, The Royal Society and the British Council. He is also the Principal Investigator for the Ulster University component in a multicentre initiative targeting the development of biosensors for the early detection of prostate cancer which was funded by the National Institutes of Health, Department of the Economy Northern Ireland and the Science Foundation Ireland

Prof Davis is a Chartered Chemist, Member of the Royal Society of Chemistry and is a Senior Fellow of the Higher Education Academy 